\title{
ALLELOPATHIC POTENTIAL OF EXTRACTS AND LEACHATES OF AZADIRACHTA INDICA A. JUSS LEAVES ON GERMINATION AND GROWTH OF ELEUSINE CORACANA (L.) GAERTNER
}

\author{
Elavazhagan, $\mathbf{P}^{*}$. \\ Botany Wing-DDE, Annamalai University, Annamalai Nagar - 608 002-Tamil Nadu. \\ *E.mail: drprabha2006@gmail.com
}

\begin{abstract}
Various concentrations $(5 \%, 10 \%, 15 \%$ and $20 \%)$ of leaf leachates and leaf extracts prepared from fully senesced fallen and matured leaves of Azadirachta indica A. Juss. and used for the present experiments to determine their allelopathic potential on growth and developmental changes on Eleusine coracana (L.) Gaertner. Leaf leachates and leaf extracts sowed an inhibitory effect on germination percentage, root and shoot growth, and fresh and dry weight of E. coracana seedlings. The leaf extracts had more inhibitory effect at $20 \%$ concentration,than that of leaf leachates on morphological parameters of E. coracana.
\end{abstract}

Keywords: Allelopathic potential, Azadirachta indica, Eleusine coracana.

\section{INTRODUCTION}

Allelopathy generally refers to the detrimental effects of higher plants of one species (the donor) on the germination, growth or development of plants of another species (the recipient) (Narwal, 1994). Molisch (1937) coined the term allelopathy from two Greek words, where allelon means 'to each other' and pathos means 'to suffer'. In natural or man managed agroecosystems, neighbouring plants may interact with the growth and development of other species. Muller (1969) suggested the term interference for the overall influence of one plant (including microorganisms) on another. In agro ecosystems, several weeds, crops, agroforestry trees and fruit trees have been shown to exert allelopathic influence on the crops, thus affecting their germination and growth adversely (Kohli et al., 1998). Allelopathy plays a key role both in natural and managed ecosystems. Eventhough allelopathy includes both positive and negative effects of one plant on the other; most of the studies seem to focus only on its deleterious impacts alone.

Joshi et al. (1996) reported that aqueous leaf extracts of Fraxinus micrantha inhibited the germination and growth of Raphanus sativus, Eleusine coracana, Triticum aestivum and Brassica campestris. Hussain et al. (1991) tested litter extracts of walnut inhibitory effect on germination of maize, turnip and bean. Aqueous extract of leaves and inflorescence of Acacia tortilis at four per cent concentration significantly reduced the pearlmillet seed germination, root and shoot length (Saxena and Sharma, 1996).The present study was aimed to determine the influence of aqueous leaf extracts and leaf leachates of Azadirachta indica A. Juss. on the seed germination and seedling growth of Eleusine coracana (L.) Gaertner.

\section{MATERIALS AND METHODS}

The preparation of dried fresh leaf extracts, leaf leachates and germination studies were followed as per the methods of Padhy et al. (2000) and Bhatt and Chauhan (2000).Leaf leachates:Twenty grams of senesced fallen leaves were collected from understory of Azadirachta indica A. Juss. tree. These leaves were washed thoroughly with tap water followed by distilled water and soaked in $100 \mathrm{ml}$ distilled water for 48 hours. The leachates were, filtered and filtrates were considered as 20\% concentration. From this leachates (20\%) further dilutions of 5, 10,15\% were prepared with distilled water. Leaf Extracts:The collected fully matured fresh leaves of Azadirachta indica A. Juss. were air dried, ground to fine powder and extracted in water. Twenty grams of ground leaf material was soaked in one litre of distilled water and kept 48 hours at room temperature with occasional shaking. The infusion was decanted and filtered through three layers of Whatman No.1 filter paper. From this leaf extracts (20\%) further dilutions of 15,10 and $5 \%$ were prepared with distilled water. The selected seeds of Eleusine coracana were surface sterilized with $0.03 \%$ formalin solution for $20 \mathrm{~min}$. and then washed thoroughly with distilled water. For the germination study 25 seeds were placed in sterilized petriplates lined with two layers of filter paper. On the first day $10 \mathrm{ml}$ of leaf extracts/Distilled Water was added per treatments on the petri plates. Distilled water served as control. Thereafter to keep the filter paper moist, $10 \mathrm{ml}$ leaf extracts/DW was added per plate 6, 9, 12 and 15 days after soaking. 
Afterwards the seeds were allowed to germinate in the growth chamber and kept in light intensity of $2 \pm 0.4 \mathrm{~K}$. Lux and at $30 \pm 2^{\circ} \mathrm{C}$ till 15 days after seed soaking. Each treatment including control was replicated five times. The number of seeds germinated in each treatment was counted daily up to $10^{\text {th }}$ day after sowing, and germination percentage was calculated. The emergence of radicle was taken as criteria for germination. Five seedlings from each replicate was selected for recording the morphological parameters such as length of shoot and root, fresh and dry weight on $15^{\text {th }}$ day after sowing.

\section{RESULTS AND DISCUSSION}

Aqueous leaf extracts and leaf leachates of Azadirachta indica caused a significant inhibition on the germination of Eleusine coracana (L) seeds over control. The intensity of inhibition differed depending upon the concentration. As the concentration of the extracts and leachates increased the degree of inhibition of the germination also increased over control (Table 1). The leaf extracts and leachates affected the germination percentage more at the higher concentration (20\%). But the effect was more intense in the treatment of leaf extracts than in aqueous leaf leachates. The extracts and leachates of leaves exhibited both inhibitory $(5,10,15,20 \%)$ effects on the germination of seeds.

Table 1. Aqueous leaf extracts and leaf leachates of $A$. indica on seed germination and seedling length(cm/plant) of E. coracana

\begin{tabular}{|c|c|c|c|c|c|c|}
\hline \multirow[b]{2}{*}{ Concentrations } & \multicolumn{2}{|c|}{ Germination \% } & \multicolumn{2}{|c|}{ Extracts } & \multicolumn{2}{|c|}{ Leachates } \\
\hline & Fvtractc & I aschatoc & $\begin{array}{c}\text { Root } \\
\text { length }\end{array}$ & $\begin{array}{l}\text { Shoot } \\
\text { length }\end{array}$ & $\begin{array}{c}\text { Root } \\
\text { length }\end{array}$ & $\begin{array}{l}\text { Shoot } \\
\text { length }\end{array}$ \\
\hline Control & 98 & 96 & 13.3 & 8.0 & 13.3 & 8.0 \\
\hline 5 & $\begin{array}{c}84 \\
(-14.3)\end{array}$ & $\begin{array}{c}86 \\
(-11.6)\end{array}$ & $\begin{array}{l}12.8 \\
(-3.7)\end{array}$ & $\begin{array}{c}7.5 \\
(-6.2)\end{array}$ & $\begin{array}{l}13.0 \\
(-2.2)\end{array}$ & $\begin{array}{c}7.3 \\
(-3.9)\end{array}$ \\
\hline $1 n$ & $\begin{array}{c}74 \\
(-24.5)\end{array}$ & $\begin{array}{c}75 \\
(-21.8)\end{array}$ & $\begin{array}{c}10.7 \\
(-19.5)\end{array}$ & $\begin{array}{c}7.0 \\
(-12.5)\end{array}$ & $\begin{array}{c}11.0 \\
(-17.3)\end{array}$ & $\begin{array}{c}6.8 \\
(-10.5)\end{array}$ \\
\hline 15 & $\begin{array}{c}60 \\
(-38.7)\end{array}$ & $\begin{array}{c}62 \\
(-35.4)\end{array}$ & $\begin{array}{c}8.8 \\
(-33.8)\end{array}$ & $\begin{array}{c}5.0 \\
(-37.5)\end{array}$ & $\begin{array}{c}9.0 \\
(-32.3)\end{array}$ & $\begin{array}{c}5.4 \\
(-29.0)\end{array}$ \\
\hline $2 n$ & $\begin{array}{c}54 \\
(-45)\end{array}$ & $\begin{array}{c}58 \\
(-39.5)\end{array}$ & $\begin{array}{c}4.7 \\
(-64.6)\end{array}$ & $\begin{array}{c}3.5 \\
(-56.2)\end{array}$ & $\begin{array}{c}5.0 \\
(-62.4)\end{array}$ & $\begin{array}{c}3.6 \\
(-52.6)\end{array}$ \\
\hline Average & 63 & 66 & 10.06 & 6.02 & 10.26 & 6.22 \\
\hline $\mathrm{F}$ & \multicolumn{2}{|c|}{196.6897} & \multicolumn{4}{|c|}{ RL-915.90,SL.263-84 } \\
\hline
\end{tabular}

Data in parenthesis indicates \% increase (+), decrease (-) over control.

Table 2. Aqueous leaf extracts and leaf leachates of Azadirachta indica A. Juss on the fresh and dry weight (mg/plant) of Eleusine coracana (L.) GAERTNER

\begin{tabular}{ccccc}
\hline \multirow{2}{*}{ Concentrations (\%) } & \multicolumn{2}{c}{ Extracts } & \multicolumn{2}{c}{ Leachates } \\
\cline { 2 - 5 } & Fresh Weight & $\begin{array}{c}\text { Dry } \\
\text { Weight }\end{array}$ & Fresh Weight & $\begin{array}{c}\text { Dry } \\
\text { Weight }\end{array}$ \\
\hline Control & 80 & 18 & 80 & 22 \\
& 74 & 15 & 76 & 19 \\
& $(-7.5)$ & $(16.6)$ & $(-5.0)$ & $(-13.6)$ \\
10 & 68 & 13.5 & 70 & 17 \\
& $(-15.0)$ & $(-25)$ & $(-12.5)$ & $(-22.7)$ \\
15 & 55 & 11 & 60 & 14 \\
& $(-31.2)$ & $(-38.8)$ & $(-25.0)$ & $(-36.3)$ \\
2n & 40 & 9.5 & 45 & 12 \\
& $(-50)$ & $(-47.2)$ & $(-43.7)$ & $(-45.4)$ \\
Average & 63.4 & 16.8 & 66.2 & 13.4 \\
\hline
\end{tabular}


Leaf extracts of several tree species are Grewia oppositifolia, Ficus roxburgh and Bauhinia variegata showed a higher rate of inhibition on the germination of maize, cowpea, finger millet and soybean (Kaleta et al., 1996). Similar inhibition of seed germination by leaf extract treatment was reported by different workers. The inhibitory effect of Acacia tortilis, Chromolena odorata, Quercus glauca and Quercus leucotrichopora on the germination of pearlmillet, cowpea, wheat, mustard and lentil (Gill et al., 1993; Bhatt and Chauhan, 2000) clearly supports the present findings.But on the contrary the study of Tripathi et al. (1998) revealed that the leaf extracts of Tectona grandis, Albizia procora and Acacia nilotica stimulated germination in soybean plant

The extracts and leachates of Azadirachta indica leaves caused inhibitory effect on the root and shoot length of Eleusine coracana (L )over control. Leaf leachates of different allelopathic tree species like, Terminalia tomentasa, Sapindus emarginatus and Azadirachta indica L. at the higher concentrations inhibit the growth of field crops. But at lower concentrations radicle growth of field crops has been promoted (Jadhav, 2003).

The bark of Tamarind tree showed strong growth inhibition in both radicles and hypocotyls of asparagus, cucumber, lettuce, radish, sesame, tomato and welsh onion (Parvez et al., 2004). The aqueous extract of aerial parts of Prunus amygdalus inhibited the growth of root and shoot length on wheat and finger millet (Pande et al., 1998).

The study of Jayakumar et al. (1998) showed that the mature trees of Ficus bengalensis produce high potential inhibitors, which will inhibit the germination of seed and seedling growth of Vigna radiata. Lower concentration (5\%) of aqueous extract of Ficus leaf and bark, enhanced the shoot and root length of Vigna radiata, but at higher concentration $(20 \%)$ of both the bark and leaf extract inhibited the germination of seed and reduce the biomass of shoot. These studies are in conformity with the present findings, because leaf leachates and leaf extracts of Azadirachta indica showed inhibition on shoot and root growth of Eleusine coracana (L ). But on the contrary the study of Tripathi et al. (1998) showed the leaf extracts of Albizia procera, Tactoria grandis and Acacia nilotica stimulated root and shoot length in soybean..

The fresh and dry weight decreased when increasing the concentrations $(10 \%, 15 \%, 20 \%)$ of leaf extracts and leaf leachates. The fresh weight of cucumber and Chinese cabbage seedlings were reduced by 58 and $52 \%$ respectively over control by full treatments of mikania leaf extract (Ismail and Kumar, 1996).

The study of Eyini et al. (1996) reveled that the leaf extract of Tephrosia purpurea, Albizzia ammara and Delonix regia inhibited that the biomass on Zea mays. The leaf leachates of Casuarina equisetifolia reduced the dry weight on rice and cowpea (Jadhav and Gayman, 1995). But the study of Mallik and Watson (1998) showed that the shoot weight of soybean were enhanced by silver nightshade residue. These studies favour the present findings. The differential degree of inhibitory $(5,10,15$ and $20 \%)$ effect on the growth of E.coracana. may be due to the presence of allelochemicals at different concentration of Azadirachta indica in both leaf extracts and leaf leachates

\section{REFERENCES}

Bhatt, B.P. and D.S. Chauhan, (2000). Allelopathic effects of Quercus spp. on crops of Garhawal Himalaya. Allelopat. J. 7(2): 265-272.

Eyini, M., A.V. Maheswari, T. Chandra, and M. Jayakumar, (1996). Allelopathic effects of leguminous plants leaf extracts on some weeds and corn. Allelopat. J. 3: 85-88.

Gill, L.S., A.R. Anoliefo, and U.V. Idaoze, (1993). Allelopathic effects of aqueous extract from stem weed on the growth of cowpea. Third International Workshop on Biocontrol and Management of Cananga Odorata held in Cote and TVIOVE.

Hussain, F., I. Ihsan, and K. Bong-Scop, (1991). Allelopathic effects of walnut plants Uuglars regia L.) on four crops species. Korean J. Bot. 34: 93-100.

Ismail, B.S and K. Kumar, (1996). Effects of aqueous extracts and residues decomposition of Mikania micrantha H.B.K. Selected crops. Allelopat. J. 3:195-2006.

Jadhav, B.B. (2003). Allelopathic effects of leaf leachates of different tree species. In: Abstract, II International Congress of Plant Physiology. p. 292.

Jadhav, B.B. and D.G. Gayman, (1995). Effect of Casuarina equisetifolia J.R. leaf litter leachates on germination and seedling growth of rice and cowpea. Allelopat. J. 2: 105-108. 
Jayakumar, M., M. Eyini, M. Manikandan, and B.S. Kil, (1998). Allelopathic effect of extracts from Ficus bengalensis. Korean J. Ecol. 21: 133-137.

Joshi, R.K., D. Prasad, C.B. Pande and M.S.M. Rawat, (1997). Allelopathic effect of root and bark extracts of Prunus jackucmontii on Raphanus sativus. Allelopat. J. 4: 329-334.

Kaleta, M.S., B.P. Bhalf and N.P. Tadaria, (1996). Tree crop interactions in traditional agroforestry systems of Garhwal Himalya. 1 Prototoxic effects of form trees on food crops. Allelopat. J. 3: $241-250$.

Kohli, R.K., D. Batish and H.P. Singh, (1998). Allelopathy and its implicationsin agroecosystems. J. Crop Prod. 1: 169-202.

Mallik, M.A.B. and C. Watson, (1998). Stimulated growth and nodulation of soybean and other plants by crop residues. Allelopat. J. 5: 13-22.

Molisch, H. (1937). Der Einfluss einer pflanze auf die andere - Allelopathic, Fisher, Jena.

Muller, C.H. (1969). Allelopathy as a factor in ecological process. Vegetation, 18: 348-357.

Narwal, S.S. (1994). Allelopathy in crop production. Scientific Publishers, Jodhpur, India.
Padhy, B., P.K. Patinaik and A.K. Tripathy, (2000). Allelopathic potential of Eucalyptus leaf litter leachates on germination and seedling growth of finger millet. Allelopat. J. 7: 69-78.

Pande, C.B., R.K. Prasad, R.K. Joshi, M.S.M. Rawat and G. Pant, (1998). Allelopathic potential of Prnus amygdalus and identification of allelochemicals. Allelopat. J. 5: 83-88.

Parvez, S.S., M.M. Parvez, Yoshiharu and H.G. Fujii, (2004). Differential allelopathic expression of bark and seed of Tamarindus indica L. Pl. Growth Regulat. 42(3): 245-253.

Saxena, A. and A.K. Sharma, (1996). Allelopathic potential of Acacia tortilis in agroforestry systems of arid regions. Allelopat.J. 3(1): 81-84.

Tripathi, S., A. Tripathi, D.C. Kori, and S. Tiwari, (1998). Effect of tree leaves aqueous extracts on germination and seedlings growth of soybean. Allelopat. J. 5(1): 75-82.

Tripathi, S., A. Tripathi, D.C. Kori, and S. Tiwari, (1998). Effect of tree leaves aqueous extracts on germination and seedlings growth of soybean. Allelopat. J. 5(1): 75-82. 